\title{
Fixed Point Approximation for Asymptotically Nonexpansive Type Mappings in Uniformly Convex Hyperbolic Spaces
}

\author{
Shin Min Kang, ${ }^{1}$ Samir Dashputre, ${ }^{2}$ Bhuwan Lal Malagar, ${ }^{2}$ and Young Chel Kwun ${ }^{3}$ \\ ${ }^{1}$ Department of Mathematics and RINS, Gyeongsang National University, Jinju 660-701, Republic of Korea \\ ${ }^{2}$ Department of Applied Mathematics, Shri Shankaracharya Group of Institutions, Junwani, Bhilai 490020, India \\ ${ }^{3}$ Department of Mathematics, Dong-A University, Busan 604-714, Republic of Korea
}

Correspondence should be addressed to Young Chel Kwun; yckwun@dau.ac.kr

Received 8 July 2014; Revised 15 September 2014; Accepted 17 September 2014

Academic Editor: Wei-Shih Du

Copyright (C) 2015 Shin Min Kang et al. This is an open access article distributed under the Creative Commons Attribution License, which permits unrestricted use, distribution, and reproduction in any medium, provided the original work is properly cited.

We use a modified $S$-iterative process to prove some strong and $\Delta$-convergence results for asymptotically nonexpansive type mappings in uniformly convex hyperbolic spaces, which includes Banach spaces and CAT( 0$)$ spaces. Thus, our results can be viewed as extension and generalization of several known results in Banach spaces and CAT(0) spaces (see, e.g., Abbas et al. (2012), Abbas et al. (2013), Bruck et al. (1993), and Xin and Cui (2011)) and improve many results in the literature.

\section{Introduction}

Let $C$ be a nonempty subset of a metric space $X$ and let $T$ : $C \rightarrow C$ be a mapping. Then, $T$ is called

(i) nonexpansive if $d(T x, T y) \leq d(x, y)$, for all $x, y \in C$,

(ii) asymptotically nonexpansive [1] if, for each $n \in \mathbb{N}$, there exists a constant $k_{n} \geq 1$ with $\lim _{n \rightarrow \infty} k_{n}=1$ such that

$$
d\left(T^{n} x_{n}, T^{n} y_{n}\right) \leq k_{n} d(x, y)
$$

for all $x, y \in C$,

(iii) nearly Lipschitzian with respect to a fixed sequence $\left\{a_{n}\right\}$, introduced by Sahu [2], if, for each $n \in \mathbb{N}$, there exists a constant $k_{n} \geq 0$ such that

$$
d\left(T^{n} x, T^{n} y\right) \leq k_{n}\left(d(x, y)+a_{n}\right),
$$

for all $x, y \in C$, where $a_{n} \in[0,1)$ for each $n$ and $a_{n} \rightarrow$ 0 . The infimum of constants $k_{n}$ satisfying (2) is called the nearly Lipschitz constant of $T^{n}$ and is denoted by $\eta\left(T^{n}\right)$, (iv) asymptotically nonexpansive in the intermediate sense [3] provided that $T$ is uniformly continuous and

$$
\limsup _{n \rightarrow \infty} \sup _{x, y \in C}\left(d\left(T^{n} x, T^{n} y\right)-d(x, y)\right) \leq 0,
$$

(v) a mapping of asymptotically nonexpansive types [4] if

$$
\limsup _{n \rightarrow \infty} \sup _{y \in C}\left(d\left(T^{n} x, T^{n} y\right)-d(x, y)\right) \leq 0
$$

for all $x \in C$.

In [3], Bruck et al. introduced the class of asymptotically nonexpansive mappings in the intermediate sense which is essentially wider than that of asymptotically nonexpansive ones [1]. It is known that [4] that if $C$ is a nonempty closed convex bounded subset of $X$ and $T: C \rightarrow C$ is asymptotically nonexpansive in the intermediate sense, then $T$ has a fixed point. Since then, many authors have studied the existence and convergence theorems of fixed points for these two classes of mappings in Banach spaces, for example, Kaczor et al. [5], Xu [6], and references in their. 
On the other hand, if $c_{n}=\max \left\{\sup _{x, y \in C}\left(d\left(T^{n} x, T^{n} y\right)-\right.\right.$ $d(x, y)), 0\}$, then (3) reduces to relation

$$
d\left(T^{n} x, T^{n} y\right) \leq d(x, y)+c_{n}
$$

for all $x, y \in C$ and $n \in \mathbb{N}$.

Remark 1 . The class of nearly asymptotically nonexpansive mappings are intermediate classes between the class of asymptotically nonexpansive mappings that of asymptotically nonexpansive in the intermediate sense mappings.

Throughout in this paper, we have worked in the setting of hyperbolic spaces introduced by Kohlenbach [7]. It is noted that they are different from Gromov hyperbolic spaces [8] or from other notions of hyperbolic spaces that can be found in literature (see, e.g., [9-11]).

A hyperbolic space $(X, d, W)$ is a metric space $(X, d)$ together with a convexity mapping $W: X^{2} \times[0,1] \rightarrow X$ satisfying

$$
\begin{aligned}
& \left(W_{1}\right) d(u, W(x, y, \alpha)) \leq \alpha d(u, x)+(1-\alpha) d(u, y), \\
& \left(W_{2}\right) d(W(x, y, \alpha), W(x, y, \beta))=|\alpha-\beta| d(x, y), \\
& \left(W_{3}\right) W(x, y, \alpha)=W(y, x, 1-\alpha), \\
& \left(W_{4}\right) d(W(x, z, \alpha), W(y, w, \alpha)) \leq(1-\alpha) d(x, y)+\alpha d(z, w),
\end{aligned}
$$

for all $x, y, z, w \in X$ and $\alpha, \beta \in[0,1]$.

A metric space is said to be a convex metric space in the sense of Takahashi [12], where a triple $(X, d, W)$ satisfies only $\left(W_{1}\right)$. We get the notion of the space of hyperbolic type in the sense of Goebel and Kirk [13], where a triple $(X, d, W)$ satisfies $\left(W_{1}\right)-\left(W_{3}\right)$. The $\left(W_{4}\right)$ was already considered by Itoh [14] under the name of "condition III" and it is used by Reich and Shafrir [11] and Kirk [10] to define their notions of hyperbolic spaces.

The class of hyperbolic spaces includes normed space and convex subsets thereof, the Hilbert space ball equipped with the hyperbolic metric [9] and Hadrmard manifold as well as the CAT(0) spaces in the sense of Gromov (see [8]).

If $x, y \in X$ and $\lambda \in[0,1]$, then we use the notation (1$\lambda) x \oplus \lambda y$ for $W(x, y, \lambda)$. The following holds even for the more general setting of convex metric space [12]: for all $x, y \in X$ and $\lambda \in[0,1]$,

$$
\begin{gathered}
d(x,(1-\lambda) x \oplus \lambda y)=\lambda d(x, y), \\
d(y,(1-\lambda) x \oplus \lambda y)=(1-\lambda) d(x, y) .
\end{gathered}
$$

A hyperbolic space $(X, d, W)$ is uniformly convex [15] if, for any $r>0$ and $\varepsilon \in(0,2]$, there exists $\delta \in(0,1]$ such that, for all $a, x, y \in X$,

$$
d\left(\frac{1}{2} x \oplus \frac{1}{2} y, a\right) \leq(1-\delta) r .
$$

Provided that $d(x, a) \leq r, d(y, a) \leq r$, and $d(x, y) \geq \varepsilon r$.

A mapping $\eta:(0, \infty) \times(0,2] \rightarrow(0,1]$, providing such a $\delta=\eta(r, \varepsilon)$ for given $r>0$ and $\varepsilon \in(0,2]$, is called a modulus of uniform convexity. We call $\eta$ monotone if it decreases with $r$ (for fixed $\varepsilon$ ).
In 1976, Lim [16] introduced a concept of convergence in a general metric space setting which he called " $\Delta$-convergence." In 2008, Kirk and Panyanak [17] specialized Lim's concept to CAT(0) spaces and showed that many Banach space results involving weak convergence have precise analogs in this setting.

In [15], Leustean proved that CAT(0) spaces are uniformly convex hyperbolic spaces with modulus of uniform convexity $\eta(r, \varepsilon)=\varepsilon^{2} / 8$ quadratic in $\varepsilon$. Thus, the classes of uniformly convex hyperbolic spaces are a natural generalization of both uniformly convex Banach spaces and CAT(0) spaces.

In the view of the above facts, many researchers have paid attention to the direction of existence and approximation of fixed points via different iterative schemes for nonexpansive, asymptotically nonexpansive, asymptotically nonexpansive type mappings, and total asymptotically nonexpansive mappings in the surrounding work of uniformly convex hyperbolic spaces (see, e.g., [10, 18-26]).

The $S$-iteration process was introduced by Agarwal et al. [27] and it has proved that the rate of convergence of $S$ iteration process is faster than that of Picard iteration process and Picard iteration process is faster than Mann iteration process for contraction mapping (see, e.g., [28], page 307).

The purpose of the paper is to establish a $\Delta$-convergence and strong convergence theorem for a modified $S$-iteration process for asymptotically nonexpansive type mappings in uniformly convex hyperbolic spaces. Our results extend and improve the corresponding ones announced by $[3,18,19,26]$ in the sense of a modified $S$-iteration process.

\section{Preliminaries}

Let $C$ be a nonempty subset of metric space $X$ and let $\left\{x_{n}\right\}$ be any bounded sequence in $C$. Consider a continuous functional $r_{a}\left(\cdot,\left\{x_{n}\right\}\right): X \rightarrow \mathbb{R}^{+}$defined by

$$
r_{a}\left(x,\left\{x_{n}\right\}\right)=\limsup _{n \rightarrow \infty} d\left(x_{n}, x\right), \quad x \in X .
$$

Then, consider the following:

(a) the infimum of $r_{a}\left(\cdot,\left\{x_{n}\right\}\right)$ over $C$ is said to be the asymptotic radius of $\left\{x_{n}\right\}$ with respect to $C$ and is denoted by $r_{a}\left(C,\left\{x_{n}\right\}\right)$;

(b) a point $z \in C$ is said to be an asymptotic center of the sequence $\left\{x_{n}\right\}$ with respect to $C$ if

$$
r_{a}\left(z,\left\{x_{n}\right\}\right)=\inf \left\{r_{a}\left(x,\left\{x_{n}\right\}\right): x \in C\right\} ;
$$

the set of all asymptotic centers of $\left\{x_{n}\right\}$ with respect to $C$ is denoted by $Z_{a}\left(C,\left\{x_{n}\right\}\right)$;

(c) this set may be empty, a singleton, or certain infinitely many points;

(d) if the asymptotic radius and the asymptotic center are taken with respect to $X$, then these are simply denoted by $r_{a}\left(X,\left\{x_{n}\right\}\right)=r_{a}\left(\left\{x_{n}\right\}\right)$ and $Z_{a}\left(X,\left\{x_{n}\right\}\right)=Z_{a}\left(\left\{x_{n}\right\}\right)$, respectively;

(e) for $x \in X, r_{a}\left(x,\left\{x_{n}\right\}\right)=0 \Leftrightarrow \lim _{n \rightarrow \infty} x_{n}=x$. 
It is known that uniformly convex Banach spaces and even CAT(0) spaces enjoy the property that bounded sequences have unique asymptotic centers with respect to closed convex subsets. The following lemma is due to Leustean [29] and ensures that this property also holds in a complete uniformly convex hyperbolic space.

Lemma 2 (see [29, Proposition 3.3]). Let $(X, d, W)$ be a complete uniformly convex hyperbolic space with monotone modulus of uniform convexity $\eta$. Then, every bounded sequence $\left\{x_{n}\right\}$ in $X$ has a unique asymptotic center with respect to any nonempty closed convex subset $C$ of $X$.

Recall that a sequence $\left\{x_{n}\right\}$ in $X$ is said to $\Delta$-converge to $x \in X$, if $x$ is the unique asymptotic center of $\left\{u_{n}\right\}$ for every subsequence $\left\{u_{n}\right\}$ of $\left\{x_{n}\right\}$. In this case, we write $\Delta-\lim _{n} x_{n}=x$ and call $x$ the $\Delta$-limit of $\left\{x_{n}\right\}$.

Lemma 3 (see [22]). Let $C$ be a nonempty closed convex subset of uniformly convex hyperbolic space $(X, d, W)$ and let $\left\{x_{n}\right\}$ be a bounded sequence in $C$ such that $Z_{a}\left(X,\left\{x_{n}\right\}\right)=\{x\}$. If $\left\{v_{m}\right\}$ is any other sequence in $C$ such that $\lim _{m \rightarrow \infty} r_{a}\left(v_{m},\left\{x_{n}\right\}\right)=$ $r_{a}\left(x,\left\{x_{n}\right\}\right)$, then $\lim _{m \rightarrow \infty} v_{m}=x$.

Lemma 4 (see [22]). Let $(X, d, W)$ be a uniformly convex hyperbolic space with monotone modulus of uniform convexity $\eta$. Let $x \in X$ and $\left\{t_{n}\right\}$ be a sequence in $[a, b]$ for some $a, b \in$ $(0,1)$. If $\left\{x_{n}\right\}$ and $\left\{y_{n}\right\}$ are sequences in $X$ such that

$$
\begin{gathered}
\limsup _{n \rightarrow \infty} d\left(x_{n}, x\right) \leq c, \quad \limsup _{n \rightarrow \infty} d\left(y_{n}, x\right) \leq c, \\
\lim _{n \rightarrow \infty} d\left(W\left(x_{n}, y_{n}, t_{n}\right), x\right)=c
\end{gathered}
$$

for some $c \geq 0$, then $\lim _{n \rightarrow \infty} d\left(x_{n}, y_{n}\right)=0$.

Lemma 5 (see [30]). Let $\left\{a_{n}\right\}$ and $\left\{b_{n}\right\}$ be two nonnegative real sequences such that

$$
a_{n+1} \leq a_{n}+b_{n} \quad \forall n \in \mathbb{N} .
$$

If $\sum_{n=1}^{\infty} b_{n}<\infty$, then $\lim _{n \rightarrow \infty} a_{n}$ exists.

Let $C$ be a nonempty convex subset of uniformly convex subset of hyperbolic space $X$ and let $T: C \rightarrow C$ be a mapping with the set of fixed points $F(T)=\{x \in C: T x=x\} \neq \phi$ and let $\left\{x_{n}\right\}$ be sequence in $C$; we say that $\left\{x_{n}\right\}$ has

$\left(D_{1}\right)$ limited existence property for $T, \lim _{n \rightarrow \infty} d\left(x_{n}, p\right)$ existing for all $p \in F(T)$;

$\left(D_{2}\right)$ approximate fixed point property for $T$, if $\lim _{n \rightarrow \infty} d$ $\left(x_{n}, T x_{n}\right)=0$.

Proposition 6. Let $(X, d, W)$ be a complete uniformly convex hyperbolic space. Let $C$ be a nonempty, closed, convex subset of $X$ and let $T: C \rightarrow C$ be asymptotically nonexpansive in the intermediate sense (provided that $T$ is uniformly continuous). Put

$$
c_{n}=\max \left\{0, \sup _{x, y \in C} d\left(T^{n} x, T^{n} y\right)-d(x, y)\right\} .
$$

If $\sum_{n=1}^{\infty} c_{n}<\infty$ and if $\left\{y_{n}\right\}$ is a bounded sequence in $C$ such that $\left(D_{2}\right)$ holds (i.e., approximate fixed property), then $T$ has a fixed point.

Proof. Let $C$ be a nonempty, closed, and convex subset of a uniformly convex hyperbolic space $X$ and let $\left\{y_{n}\right\}$ be a bounded sequence in $C$; therefore, by Lemma $2, Z_{a}\left(C,\left\{y_{n}\right\}\right)$ consists exactly of one point $v$ (say). We now show that $v$ is a fixed point of $T$. Since $\left\{y_{n}\right\}$ has an approximate sequence for $T$, therefore, by the uniform continuity of $T$, it implies that

$$
\lim _{n \rightarrow \infty} d\left(T^{i} y_{n}, T^{i+1} y_{n}\right)=0 \quad \text { for } i=0,1,2, \ldots
$$

We define a sequence in $C$ by $z_{m}=T^{m} \nu, m \in \mathbb{N}$. For integers $m, n \in \mathbb{N}$, we have

$$
\begin{aligned}
d\left(z_{m}, y_{n}\right) \leq & d\left(T^{m} v, T^{m} y_{n}\right)+d\left(T^{m} y_{n}, T^{m-1} y_{n}\right) \\
& +\cdots+d\left(T y, y_{n}\right) \\
\leq & d\left(\nu, y_{m}\right)+c_{m}+\sum_{i=0}^{m-1} d\left(T^{i} y_{n}, T^{i+1} y_{n}\right) .
\end{aligned}
$$

Taking limit as superior as $m \rightarrow \infty$ on both sides, using (13) and (14), we have

$$
\begin{aligned}
& r_{a}\left(z_{m},\left\{y_{n}\right\}\right) \\
& \quad=\limsup _{m \rightarrow \infty} d\left(z_{m}, y_{n}\right) \\
& \quad \leq \limsup _{m \rightarrow \infty}\left[d\left(\nu, y_{n}\right)+c_{m}+\sum_{i=0}^{m-1} d\left(T^{i} y_{n}, T^{i+1} y_{n}\right)\right] .
\end{aligned}
$$

Hence,

$$
r_{a}\left(z_{m},\left\{y_{n}\right\}\right) \leq r_{a}\left(\nu,\left\{y_{n}\right\}\right)
$$

This implies that

$$
\left|r_{a}\left(z_{m},\left\{y_{n}\right\}\right)-r_{a}\left(\nu,\left\{y_{n}\right\}\right)\right| \longrightarrow 0 \quad \text { as } m \longrightarrow \infty .
$$

It follows from Lemma 3 that $T^{m} v \rightarrow v$ as $m \rightarrow \infty$. Since $C$ is closed, therefore, $\lim _{n \rightarrow \infty} T^{m} v=v \in C$. By continuity of $T$, we have

$$
T \nu=T\left(\lim _{m \rightarrow \infty} T^{m} v\right)=\lim _{m \rightarrow \infty} T^{m+1} v=v ;
$$

that is, $T$ has fixed point.

\section{3. $\Delta$-Convergence and Strong Convergence Theorems in Hyperbolic Space}

Now we establish $\Delta$-convergence and strong convergence theorems for a modified $S$-iteration process in uniformly convex hyperbolic spaces.

In [27], Agarwal et al. introduced a modified $S$-iteration process in the setting of a Banach space. Now, we define a modified $S$-iteration process in the notion of a uniformly convex hyperbolic space as follows. 
Let $C$ be a nonempty closed convex subset of a uniformly convex hyperbolic space $X$ and let $T: C \rightarrow C$ be total asymptotically nonexpansive mappings. Then, for arbitrarily chosen $x_{1} \in C$, we construct a sequence $\left\{x_{n}\right\}$ in $C$ such that

$$
\begin{gathered}
x_{n+1}=W\left(T^{n} x_{n}, T^{n} y_{n}, \alpha_{n}\right), \\
y_{n}=W\left(x_{n}, T^{n} x_{n}, \beta_{n}\right), \quad n \in \mathbb{N},
\end{gathered}
$$

where $\left\{\alpha_{n}\right\}$ and $\left\{\beta_{n}\right\}$ are sequences in $(0,1)$ which is called a modified $S$-iteration process.

Lemma 7. Let $C$ be a nonempty closed convex subset of a uniformly convex hyperbolic space $X$. Let $T: C \rightarrow C$ be uniformly continuous asymptotically nonexpansive in the intermediate sense. Put

$$
c_{n}=\max \left\{0, \sup _{x, y \in C} d\left(T^{n} x, T^{n} y\right)-d(x, y)\right\} .
$$

If $\sum_{n=1}^{\infty} c_{n}<\infty$, let $\left\{x_{n}\right\}$ be the modified $S$-iteration process in $C$ defined by (19) having limited existence property for $T$, where $\left\{\alpha_{n}\right\}$ and $\left\{\beta_{n}\right\}$ are real sequences in $(0,1)$ such that $0<a \leq$ $\alpha_{n} \leq \beta_{n} \leq b<1$.

Proof. Let $p \in \operatorname{Fix}(T)$. From (19), we have

$$
\begin{aligned}
d\left(x_{n+1}, p\right) & =d\left(W\left(T^{n} x_{n}, T^{n} y_{n}, \alpha_{n}\right), p\right) \\
& \leq\left(1-\alpha_{n}\right) d\left(T^{n} x_{n}, p\right)+\alpha_{n} d\left(T^{n} y_{n}, p\right) \\
& \leq\left(1-\alpha_{n}\right) d\left(x_{n}, p\right)+\alpha_{n} d\left(y_{n}, p\right)+c_{n} \\
& \leq\left(1-\alpha_{n}\right) d\left(x_{n}, p\right)+\alpha_{n} d\left(y_{n}, p\right)+c_{n}, \\
d\left(y_{n}, p\right) & =d\left(W\left(x_{n}, T^{n} x_{n}, \beta_{n}\right), p\right) \\
& \leq\left(1-\beta_{n}\right) d\left(x_{n}, p\right)+\beta_{n}\left(d\left(x_{n}, p\right)+c_{n}\right) \\
& \leq d\left(x_{n}, p\right)+\beta_{n} c_{n},
\end{aligned}
$$

from (21) and (22), we have

$$
\begin{aligned}
d\left(x_{n+1}, p\right) \leq & \left(1-\alpha_{n}\right) d\left(x_{n}, p\right) \\
& +\alpha_{n}\left(d\left(x_{n}, p\right)+\beta_{n} c_{n}\right)+c_{n} \\
\leq & d\left(x_{n}, p\right)+c_{n}\left(1+\alpha_{n} \beta_{n}\right) .
\end{aligned}
$$

It follows that

$$
d\left(x_{n+1}, p\right) \leq d\left(x_{n}, p\right)+a_{n} M
$$

for some $M \geq 0$. Hence, by Lemma 5, we observe that $\lim _{n \rightarrow \infty} d\left(x_{n}, p\right)$ exists for each $p \in F(T)$. Hence, sequence $\left\{x_{n}\right\}$ has limited existence property for map $T$. This completes the proof.

Lemma 8. Let $C$ be a nonempty closed and convex subset of a uniformly convex hyperbolic space $X$ with monotone modulus of uniform convexity $\eta$ and let $T: C \rightarrow C$ be uniformly continuous asymptotically nonexpansive in the intermediate sense. Put

$$
c_{n}=\max \left\{0, \sup _{x, y \in C} d\left(T^{n} x, T^{n} y\right)-d(x, y)\right\} .
$$

If $\sum_{n=1}^{\infty} c_{n}<\infty$, let $\left\{x_{n}\right\}$ be the modified $S$-iteration process in $C$ defined by (19) having approximate fixed point property, where $\left\{\alpha_{n}\right\}$ and $\left\{\beta_{n}\right\}$ are real sequences in $(0,1)$ such that $0<a \leq$ $\alpha_{n} \leq \beta_{n} \leq b<1$.

Proof. It follows from Lemma 7 that $\lim _{n \rightarrow \infty} d\left(x_{n}, p\right)$ exists and $\left\{x_{n}\right\}$ is bounded, so, without loss of generality, we can assume that $\lim _{n \rightarrow \infty} d\left(x_{n}, p\right)=c$ for some $c \in \mathbb{R}$. If $r=0$, then we immediately obtain

$$
d\left(x_{n}, T x_{n}\right) \leq d(x, p)+d\left(T x_{n}, p\right)
$$

and, hence, by uniform continuity of $T$, we have $\lim _{n \rightarrow \infty} d$ $\left(x_{n}, T x_{n}\right)=0$. If $c>0$, then, from definition of $T$, we get

$$
\begin{aligned}
d\left(T^{n} x_{n}, p\right) & =d\left(T^{n} x_{n}, T^{n} p\right) \\
& \leq d\left(x_{n}, p\right)+c_{n}
\end{aligned}
$$

for all $n \in \mathbb{N}$. Taking limit as superior as $n \rightarrow \infty$ on both sides, we get

$$
\limsup _{n \rightarrow \infty} d\left(T^{n} x_{n}, p\right) \leq c .
$$

From (22), we have

$$
d\left(y_{n}, p\right) \leq d\left(x_{n}, p\right)+\beta_{n} c_{n}
$$

for all $n \in \mathbb{N}$. Taking limit as superior as $n \rightarrow \infty$ on both sides, we get

$$
\limsup _{n \rightarrow \infty} d\left(y_{n}, p\right) \leq c .
$$

Hence, from (30), we have

$$
\limsup _{n \rightarrow \infty} d\left(T^{n} y_{n}, p\right) \leq \limsup _{n \rightarrow \infty}\left[d\left(y_{n}, p\right)+c_{n}\right] \leq c .
$$

Since

$$
\begin{aligned}
c & =\lim _{n \rightarrow \infty} d\left(x_{n+1}, p\right) \\
& =\lim _{n \rightarrow \infty} d\left(W\left(T^{n} x_{n}, T^{n} y_{n}, \alpha_{n}\right), p\right),
\end{aligned}
$$

using Lemma 4, (28), and (31), it follows that

$$
\lim _{n \rightarrow \infty} d\left(T^{n} x_{n}, T^{n} y_{n}\right)=0
$$


From (19) and (33), we get

$$
\begin{aligned}
d\left(x_{n+1}, T^{n} x_{n}\right) & =d\left(W\left(T^{n} x_{n}, T^{n} y_{n}, \alpha_{n}\right), T^{n} x_{n}\right) \\
& \leq b d\left(T^{n} y_{n}, T^{n} x_{n}\right) \longrightarrow 0 \quad \text { as } n \longrightarrow \infty
\end{aligned}
$$

Hence,

$$
\begin{aligned}
& d\left(x_{n+1}, T^{n} y_{n}\right) \\
& \quad \leq d\left(x_{n+1}, T^{n} x_{n}\right)+d\left(T^{n} x_{n}, T^{n} y_{n}\right) \longrightarrow 0 \quad \text { as } n \longrightarrow \infty .
\end{aligned}
$$

Now, we observe that

$$
\begin{aligned}
d\left(x_{n+1}, p\right) & \leq d\left(x_{n+1}, T^{n} y_{n}\right)+d\left(T^{n} y_{n}, p\right) \\
& \leq d\left(x_{n+1}, T^{n} y_{n}\right)+d\left(y_{n}, p\right)+c_{n},
\end{aligned}
$$

which gives from (36) that

$$
c \leq \liminf _{n \rightarrow \infty} d\left(y_{n}, p\right) .
$$

The estimates of (30) and (37) imply that

$$
\begin{aligned}
c & =\lim _{n \rightarrow \infty} d\left(y_{n}, p\right) \\
& =\lim _{n \rightarrow \infty} d\left(W\left(x_{n}, T^{n} x_{n}, \beta_{n}\right), p\right) .
\end{aligned}
$$

It follows from Lemma 4 that we have

$$
\lim _{n \rightarrow \infty} d\left(x_{n}, T^{n} x_{n}\right)=0 .
$$

From (33) and (39), we get

$$
\lim _{n \rightarrow \infty} d\left(x_{n+1}, x_{n}\right)=0 .
$$

Thus, we have

$$
\begin{aligned}
d\left(x_{n}, T x_{n}\right) \leq & d\left(x_{n}, x_{n+1}\right)+d\left(x_{n+1}, T^{n+1} x_{n+1}\right) \\
& +d\left(T^{n+1} x_{n+1}, T^{n+1} x_{n}\right) \\
& +d\left(T^{n+1} x_{n}, T x_{n}\right) \\
\leq & d\left(x_{n}, x_{n+1}\right)+d\left(x_{n+1}, T^{n+1} x_{n+1}\right) \\
& +d\left(x_{n+1}, x_{n}\right) \\
& +c_{n+1}+d\left(T^{n+1} x_{n}, T x_{n}\right) .
\end{aligned}
$$

By (34), (40), and the uniform continuity of $T, d\left(x_{n}, T x_{n}\right) \rightarrow$ 0 as $n \rightarrow \infty$ implies that $d\left(T^{n} x_{n}, T^{n+1} x_{n}\right) \rightarrow 0$ as $n \rightarrow \infty$; we conclude that

$$
d\left(x_{n}, T x_{n}\right) \longrightarrow 0 \text { as } n \longrightarrow \infty \text {. }
$$

It shows that sequence $\left\{x_{n}\right\}$ has an approximate fixed point property for map $T$ (i.e., $\left(D_{2}\right)$ holds).
Theorem 9. Let $C$ be a nonempty closed, convex subset of a complete uniformly convex hyperbolic space $X$ with monotone modulus of uniform convexity $\eta$ and let $T: C \rightarrow C$ be uniformly continuous asymptotically nonexpansive in the intermediate sense. Put

$$
c_{n}=\max \left\{0, \sup _{x, y \in C} d\left(T^{n} x, T^{n} y\right)-d(x, y)\right\} .
$$

If $\sum_{n=1}^{\infty} c_{n}<\infty$. Let $\left\{x_{n}\right\}$ be the modified $S$-iteration process in $C$ defined by (19), where $\left\{\alpha_{n}\right\}$ and $\left\{\beta_{n}\right\}$ are real sequences in $(0,1)$ such that $0<a \leq \alpha_{n} \leq \beta_{n} \leq b<1$. Then, $\left\{x_{n}\right\}$ is $\Delta$-convergent to an element of $F(T)$.

Proof. It follows from Lemma 7 that $\left\{x_{n}\right\}$ is bounded. Therefore, by Lemma 2, one has unique asymptotic center that $Z_{a}\left(C,\left\{x_{n}\right\}\right)=\{x\}$. Let $\left\{u_{n}\right\}$ be any subsequence of $\left\{x_{n}\right\}$ such that $Z_{a}\left(C,\left\{u_{n}\right\}\right)=\{u\}$ and, hence, by Lemma 8 , we have $\lim _{n \rightarrow \infty} d\left(u_{n}, T u_{n}\right)=0$. Hence, by Proposition 6, we have, $u \in F(T)$.

Next, we claim that $v$ is the unique asymptotic center for each subsequence $\left\{u_{n}\right\}$ of $\left\{x_{n}\right\}$. Assume contrarily that $x \neq v$. Since $\lim _{n \rightarrow \infty} d\left(x_{n}, v\right)$ exists by Lemma 7 , therefore, by the uniqueness of asymptotic centers, we have

$$
\begin{aligned}
\limsup _{n \rightarrow \infty} d\left(u_{n}, v\right) & <\limsup _{n \rightarrow \infty} d\left(u_{n}, x\right) \\
& \leq \limsup _{n \rightarrow \infty} d\left(x_{n}, x\right) \\
& <\limsup _{n \rightarrow \infty} d\left(x_{n}, v\right) \\
& =\limsup _{n} d\left(u_{n}, v\right),
\end{aligned}
$$

a contradiction and, hence, $x=v$. Since $\left\{u_{n}\right\}$ is an arbitrary subsequence of $\left\{x_{n}\right\}$, therefore, $Z_{a}\left(C,\left\{u_{n}\right\}\right)=\{u\}$ for all subsequences of $\left\{u_{n}\right\}$ of $\left\{x_{n}\right\}$. This proves that $\left\{x_{n}\right\} \Delta$ converges to a fixed point of $T$.

Theorem 10. Let $X, C, T$, and $\left\{x_{n}\right\}$ be defined as in Theorem 9. Then, $\left\{x_{n}\right\}$ converges strongly to a fixed point of $T$ if and only if $\lim _{n \rightarrow \infty} d\left(x_{n}, F(T)\right)=0$.

Proof. Necessity is obvious. We only prove the sufficiency. have

Suppose that liminf $\operatorname{in}_{n \rightarrow \infty} d\left(x_{n}, F(T)\right)=0$, from (24), we

$$
d\left(x_{n+1}, F(T)\right) \leq d\left(x_{n}, F(T)\right)+M c_{n}, \quad n \in \mathbb{N},
$$

for some $M \geq 0$. It follows, from Lemma 5, that $\lim _{n \rightarrow \infty} d$ $\left(x_{n}, F(T)\right)$ exists. It follows that $\lim _{n \rightarrow \infty} d\left(x_{n}, F(T)\right)=0$. Next, we show that $\left\{x_{n}\right\}$ is a Cauchy sequence. Now, we can choose a subsequence $\left\{x_{n_{k}}\right\}$ of $\left\{x_{n}\right\}$ such that

$$
d\left(x_{n_{k}}, p\right)<2^{-k}
$$

for all integer $k \geq 1$ and some $p_{k}$ on $F(T)$. Again, from (24), applying Lemma 5, we have

$$
d\left(x_{n_{k+1}}, p_{k}\right) \leq d\left(x_{n_{k}}, p_{k}\right)+M c_{n_{k}}<2^{-k}
$$


and, hence,

$$
\begin{aligned}
d\left(p_{k+1}, p_{k}\right) & \leq d\left(p_{k+1}, x_{n_{k+1}}\right)+d\left(x_{n_{k+1}}, p_{k}\right) \\
& \leq 2^{-(k+1)}+2^{-k}<2^{-k+1},
\end{aligned}
$$

which shows that $\left\{p_{k}\right\}$ is a Cauchy sequence in closed subset $C$ of a complete uniformly convex hyperbolic space and so it must converge strongly to a point $p$ in $F(T)$. It is readily seen that $\left\{x_{n_{k}}\right\}$ and $\left\{x_{n}\right\}$ converge strongly to $p$.

Recall that a mapping $T$ from a subset of a metric space $(X, d)$ into itself with $F(T) \neq \phi$ is said to satisfy condition (A) (see [31]) if there exists a nondecreasing function $f$ : $[0, \infty) \rightarrow[0, \infty)$ with $f(0)=0$ and $f(t)>0$ for $t \in(0, \infty)$ such that

$$
d(x, T x) \geq f(d(x, F(T)))
$$

for all $x \in C$.

Theorem 11. Let $X, C, T$, and $\left\{x_{n}\right\}$ be defined as in Theorem 9 . Suppose that $T$ satisfies condition $(A)$. Then, $\left\{x_{n}\right\}$ converges strongly to a fixed point of $T$.

Proof. Note that sequence $\left\{x_{n}\right\}$ has approximate fixed point property for $T$; that is, $\lim _{n \rightarrow \infty} d\left(x_{n}, T x_{n}\right)=0$. Further, by condition $(A)$,

$$
\lim _{n \rightarrow \infty} d\left(x_{n}, T x_{n}\right) \geq \lim _{n \rightarrow \infty} f\left(d\left(x_{n}, F(T)\right)\right) .
$$

It follows that $\lim _{n \rightarrow \infty} d\left(x_{n}, F(T)\right)=0$. Therefore, the result follows from Theorem 10.

Remark 12. In the view of Remark 1, Theorems 9, 10, and 11 generalize and extend the results of $[3,18,19,26]$ in the sense a modified $S$-iteration process which is faster than other iteration processes (see, e.g., Mann and Ishikawa) in the setting of unifromly convex hyperbolic spaces.

\section{Conflict of Interests}

The authors declare that there is no conflict of interests regarding the publication of this paper.

\section{Acknowledgments}

The authors would like to thank the referees for useful comments and suggestions. This study was supported by research funds from Dong-A University.

\section{References}

[1] K. Goebel and W. A. Kirk, "A fixed point theorem for asymptotically nonexpansive mappings," Proceedings of the American Mathematical Society, vol. 35, pp. 171-174, 1972.

[2] D. R. Sahu, "Fixed points of demicontinuous nearly Lipschitzian mappings in Banach spaces," Commentationes Mathematicae Universitatis Carolinae, vol. 46, no. 4, pp. 653-666, 2005.
[3] R. Bruck, T. Kuczumow, and S. Reich, "Convergence of iterates of asymptotically nonexpansive mappings in Banach spaces with the uniform opial property," Colloquium Mathematicum, vol. 65, no. 2, pp. 169-179, 1993.

[4] W. A. Kirk, "Fixed point theorems for non-Lipschitzian mappings of asymptotically nonexpansive type," Israel Journal of Mathematics, vol. 17, pp. 339-346, 1974.

[5] W. Kaczor, T. Kuczumow, and S. Reich, "A mean ergodic theorem for mappings which are asymptotically nonexpansive in the intermediate sense," Nonlinear Analysis: Theory, Methods \& Applications, vol. 47, no. 4, pp. 2731-2742, 2001.

[6] H.-K. Xu, "Existence and convergence for fixed points of mappings of asymptotically nonexpansive type," Nonlinear Analysis: Theory, Methods \& Applications, vol. 16, no. 12, pp. 1139-1146, 1991.

[7] U. Kohlenbach, "Some logical metatheorems with applications in functional analysis," Transactions of the American Mathematical Society, vol. 357, no. 1, pp. 89-128, 2005.

[8] M. R. Bridson and A. Haefliger, Metric Spaces of Non-Positive Curvature, Springer, 1999.

[9] K. Goebel and S. Reich, Uniform Convexity, Hyperbolic Geometry and Nonexpansive Mappings, vol. 83 of Monographs and Textbooks in Pure and Applied Mathematics, Marcel Dekker, New York, NY, USA, 1984.

[10] W. A. Kirk, "Krasnosel'sk's iteration process in hyperbolic space," Numerical Functional Analysis and Optimization, vol. 4, no. 4, pp. 371-381, 1981/82.

[11] S. Reich and I. Shafrir, "Nonexpansive iterations in hyperbolic spaces," Nonlinear Analysis, vol. 15, no. 6, pp. 537-558, 1990.

[12] W. A. Takahashi, "A convexity in metric space and nonexpansive mappings. I," Kodai Mathematical Seminar Reports, vol. 22, no. 2, pp. 142-149, 1970.

[13] K. Goebel and W. A. Kirk, "Iteration processes for nonexpansive mappings," in Topological Methods in Nonlinear Functional Analysis (Toronto, 1982), S. P. Singh, S. Thomeier, and B. Watson, Eds., vol. 21 of Contemporary Mathematics, pp. 115-123, American Mathematical Society, Providence, RI, USA, 1983.

[14] S. Itoh, "Some fixed-point theorems in metric spaces," Fundamenta Mathematicae, vol. 102, no. 2, pp. 109-117, 1979.

[15] L. Leustean, "A quadratic rate of asymptotic regularity for CAT(0)-spaces," Journal of Mathematical Analysis and Applications, vol. 325, no. 1, pp. 386-399, 2007.

[16] T. C. Lim, "Remarks on some fixed point theorems," Proceedings of the American Mathematical Society, vol. 60, pp. 179-182, 1976.

[17] W. A. Kirk and B. Panyanak, "A concept of convergence in geodesic spaces," Nonlinear Analysis: Theory, Methods and Applications, vol. 68, no. 12, pp. 3689-3696, 2008.

[18] M. Abbas, Z. Kadelburg, and D. R. Sahu, "Fixed point theorems for Lipschitzian type mappings in CAT(0) spaces," Mathematical and Computer Modelling, vol. 55, no. 3-4, pp. 1418-1427, 2012.

[19] M. Abbas, B. S. Thakur, and D. Thakur, "Fixed points of asymptotically nonexpansive mappings in the intermediate sense in CAT(0) space," Communications of the Korean Mathematical Society, vol. 28, no. 1, pp. 107-121, 2013.

[20] H. Fukhar-ud-din and M. A. A. Khan, "Convergence analysis of a general iteration schema of nonlinear mappings in hyperbolic spaces," Fixed Point Theory and Applications, vol. 2013, article 238, 2013.

[21] H. Fukhar-Ud-Din and A. Kalsoom, "Fixed point approximation of asymptotically nonexpansive mappings in hyperbolic spaces," Fixed Point Theory and Applications, vol. 2014, article 64, 2014. 
[22] A. R. Khan, H. Fukhar-ud-din, and M. A. A. Khan, "An implicit algorithm for two finite families of nonexpansive maps in hyperbolic spaces," Fixed Point Theory and Applications, vol. 2012, article 54, 2012.

[23] A. R. Khan, H. Fukhar-ud-din, A. Kalsoom, and B. S. Lee, "Convergence of a general algorithm of asymptotically nonexpansive maps in uniformly convex hyperbolic spaces," Applied Mathematics and Computation, vol. 238, pp. 547-556, 2014.

[24] L. L. Wan, " $\Delta$-convergence for mixed-type total asymptotically nonexpansive mappings in hyperbolic spaces," Journal of Inequalities and Applications, vol. 2013, no. 553, 8 pages, 2013.

[25] L.-C. Zhao, S.-S. Chang, and J. K. Kim, "Mixed type iteration for total asymptotically nonexpansive mappings in hyperbolic spaces," Fixed Point Theory and Applications, vol. 2013, article 353, 2013.

[26] J. Xin and Y. Cui, "Existence and convergence of fixed points for mappings of asymptotically nonexpansive type in uniformly convex W-hyperbolic spaces," Fixed Point Theory and Applications, vol. 2011, article 39, 12 pages, 2011.

[27] R. P. Agarwal, D. O’Regan, and D. R. Sahu, "Iterative construction of fixed points of nearly asymptotically nonexpansive mappings," Journal of Nonlinear and Convex Analysis, vol. 8, no. 1, pp. 61-79, 2007.

[28] R. P. Agarwal, D. O'Regan, and D. R. Sahu, Fixed Point Theory for Lipschitizian-Type Mappings with Applications, vol. 6 of Topological Fixed Point Theory and Its Applications, Springer, New York, NY, USA, 2009.

[29] L. Leustean, "Nonexpansive iteration in uniformly convex $W$ hyperbolic spaces," in Nonlinear Analysis and Optimization I: Nonlinear Analysis, A. Leizarowitz, B. S. Mordukhovich, I. Shafrir, and A. Zaslavski, Eds., vol. 513, pp. 193-210, American Mathematical Society, Providence, RI, USA, 2010.

[30] K. K. Tan and H. K. Xu, "Approximating fixed points of nonexpansive mappings by the Ishikawa iteration process," Journal of Mathematical Analysis and Applications, vol. 178, no. 2, pp. 301-308, 1993.

[31] H. F. Senter and J. Dotson, "Approximating fixed points of nonexpansive mappings," Proceedings of the American Mathematical Society, vol. 44, pp. 375-380, 1974. 


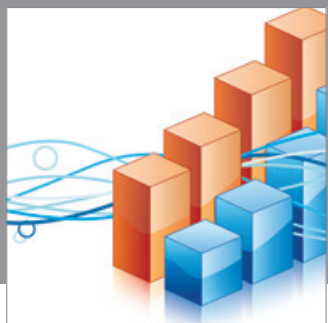

Advances in

Operations Research

mansans

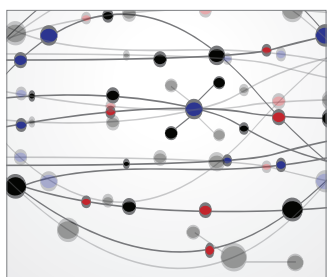

The Scientific World Journal
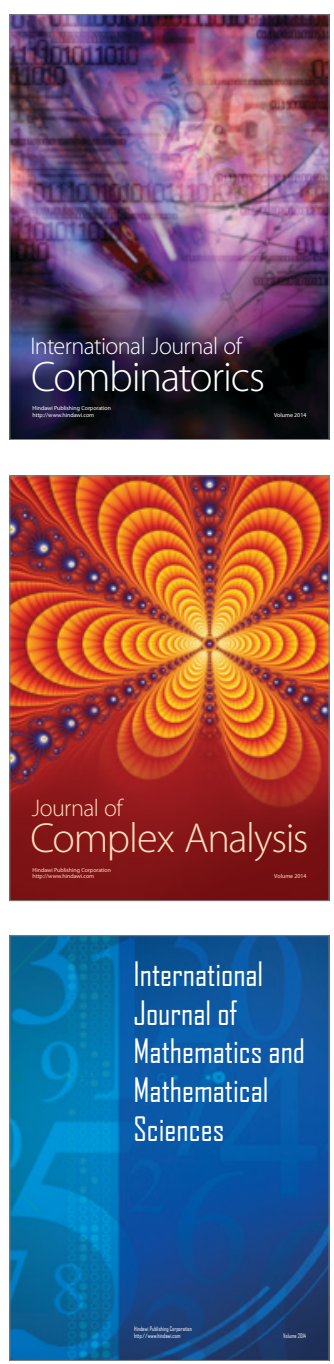
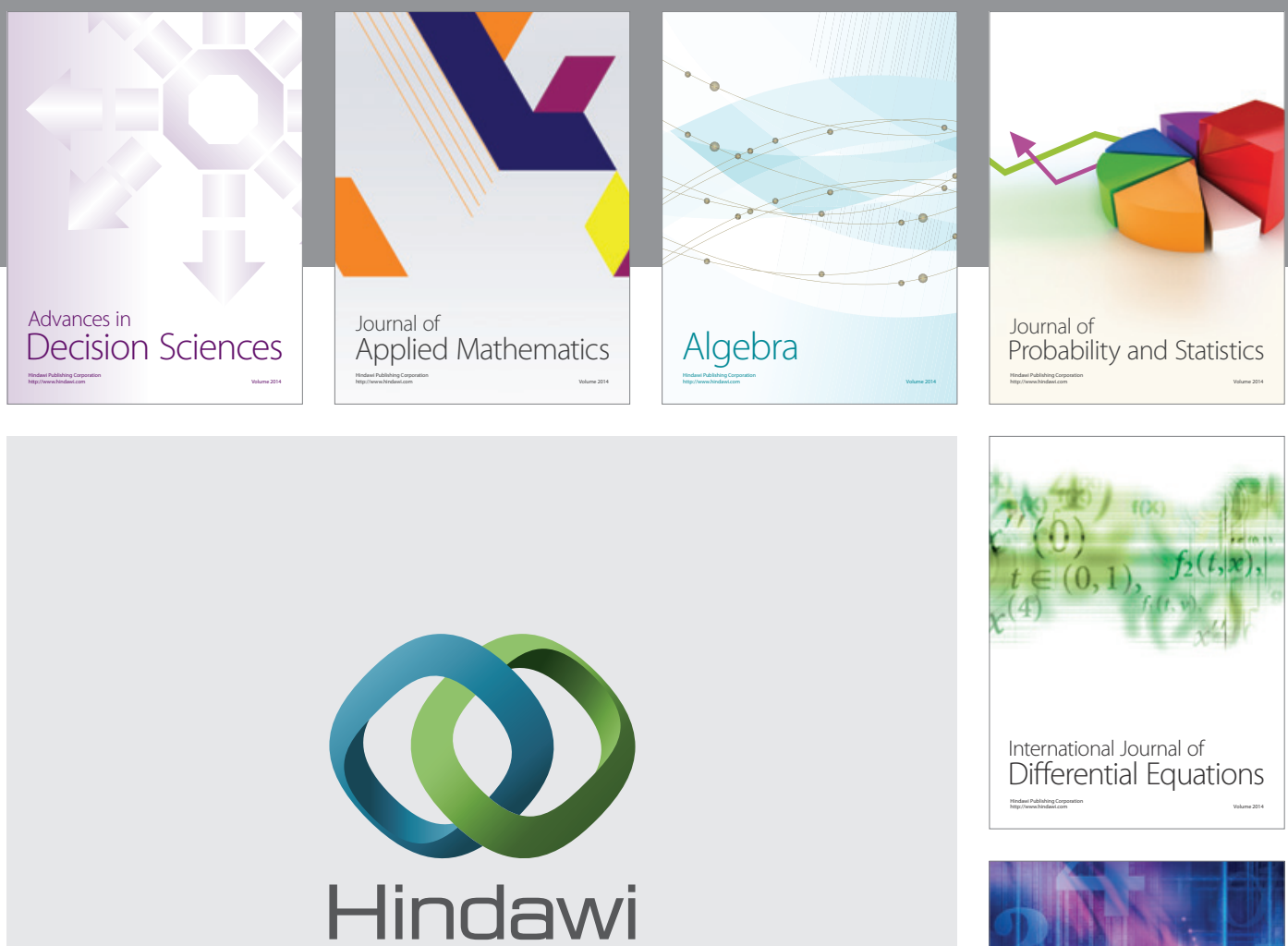

Submit your manuscripts at http://www.hindawi.com
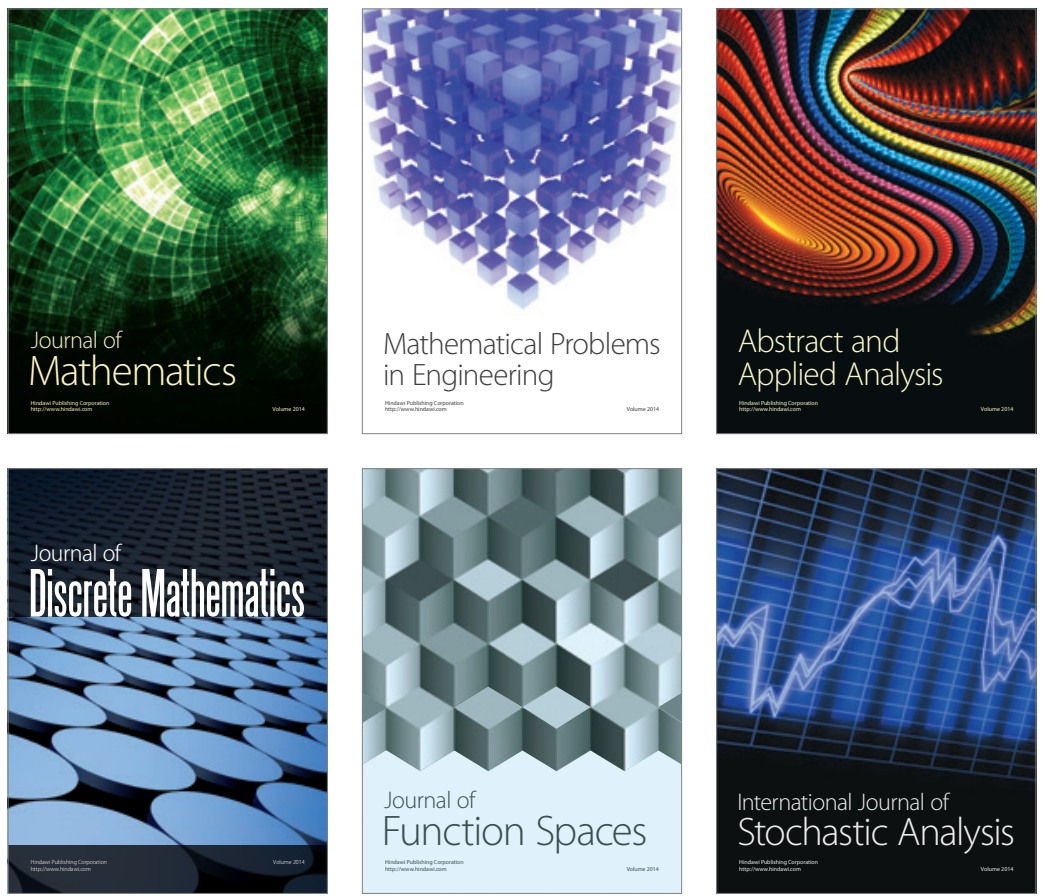

Journal of

Function Spaces

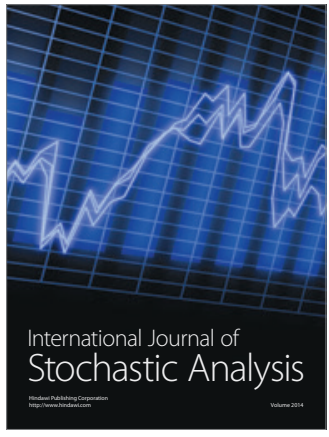

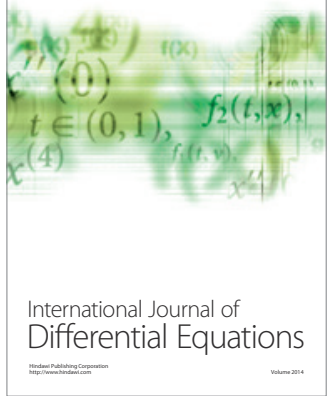
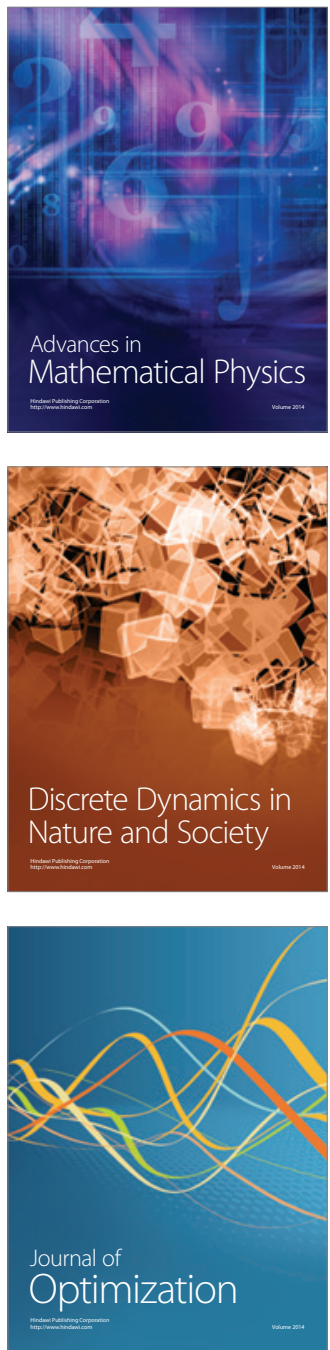